\title{
Zur Einleitung
}

Der Übersetzung des Genesiskommentars habe ich eine eigene Einleitung zu Autor und Werk beigegeben, vor allem, weil es mir darauf ankam, die Einleitung der Edition mit neuen Gesichtspunkten anzureichern. Auch die Grundsätze der Übersetzung wurden dort skizziert. Da beim Exoduskommentar Edition und Übersetzung in schneller Folge erscheinen, verweise ich hier nur auf die bisherigen Einleitungen. An der Stelle einer eigenen Einleitung erscheinen hier nur eine Anmerkung zur Reihenfolge und das Abkürzungsverzeichnis.

\section{Anmerkung zur Reihenfolge der ausgelegten Bibelverse}

Anders, als man für einen Exoduskommentar erwartet, folgt die Auslegung nicht überall der Reihenfolge der biblischen Verse. Der Grund dafür ist, dass Prokop streckenweise als Hauptvorlage nicht mehr die Urkatene als Hauptvorlage benutzte, sondern die Schrift De adoratione et cultu in spiritu et ueritate des Kyrill. Die Gründe und Details wurden in der Einleitung zur Edition dargelegt. Damit bei der Benutzung der Übersetzung möglichst wenig Verwirrung entsteht, wurde (neben den Hinweisen im Text und im Inhaltsverzeichnis) zu allen Überschriften zwischen Kapitel 25 und 31 der Zusatz „umgestellt“ hinzugefügt (auch wenn mit Kapitel 26 eine gewisse Ordnung eintritt).

\section{Abkürzungen und Zeichen}

Die wenigen hier gebrauchten Abkürzungen und Zeichen dürften bekannt sein; die Verwendung der folgenden ist allerdings zentral für die Benutzung der Übersetzung:

‘..) Übersetzung einer Hinzufügung zum griechischen Text (Konjektur)

[d. h. ...] das heißt: erläuternde Ergänzung ohne Textgrundlage

(sc. ...) scilicet: Ergänzung zum besseren Verständnis, die aus dem griechischen Text hervorgeht 
Die Anführungszeichen scheinen mir ein wichtiger Orientierungspunkt zu sein, um die verschiedenen Ebenen von ausgelegtem Bibeltext, Beweis durch Bibelverse und Erklärung durch Paraphrase zu unterscheiden:

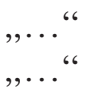

Zitat aus dem an dieser Stelle kommentierten Bibeltext (Lemma) Sonstige Zitate, z.B. ein Bibelzitat, das nicht Lemmazitat ist; sonstige griechische Übersetzer des Alten Testaments; nichtbiblische Zitate

'..' Mit diesen Anführungszeichen werden verschiedene Zitatarten gekennzeichnet, darunter ein fingierter Wortlaut, der sich gerade nicht in der Bibel findet, ${ }^{1}$ ein Begriff, ${ }^{2}$ eine Übersetzung, z. B. eines griechischen Begriffes ${ }^{3}$ oder eines hebräischen oder syrischen Wortes oder Satzes $;^{4}$ eine Umschrift $;{ }^{5}$ eine etymologische oder biblische Deutung eines nichtgriechischen Wortes ${ }^{6}$ oder die Anspielung auf eine solche Deutung, ${ }^{7}$ die Ergänzung ${ }^{8}$ oder die

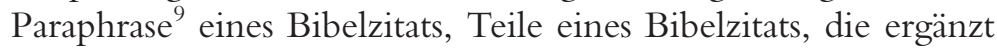
oder in anderer Hinsicht nicht wörtlich zitiert werden. ${ }^{10}$

1 Beispiel: „Sie stöhnten“ aber weder 'wegen des Ziegelbrennens' noch 'wegen des Lehms' noch 'wegen des Strohs', sondern ,wegen der Arbeiten.“

2 Beispiel: ... wo ein 'Anfang' ist, ist er nicht unbedingt auch 'das Erste'.

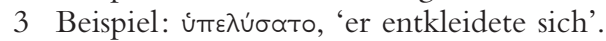

4 Beispiel: „Reguël“, was mit 'Hirtenamt Gottes' übersetzt wird.

5 Beispiele: ägyptisch 'mos', hebräisch 'phasé'.

6 Beispiel: Bedeutung des Namens Zippora: 'Betrachtung'.

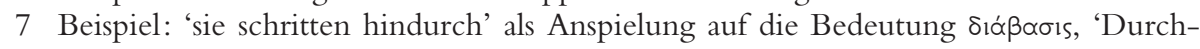
querung, Hindurchschreiten, Passage', des Wortes máox $\alpha$, 'Passahfest'.

8 Beispiel: „Ich sah“ 'und hörte' „die Misshandlung des Volkes“.

9 Beispiel: Manche aber sagen, dass ihm Gott klarmache: 'Du wirst die Ägypter niedertreten und mich, wenn du zurückkehrst, mit Lob anbeten'.

10 Z. B. in folgendem Zitat: „Ich aber wurde zum König“ 'über sie' „eingesetzt auf seinem heiligen Berg Zion." 